\title{
Calculation of Shielding Effectiveness of Materials for Security Devices
}

\author{
Stanislav Kovar*, Jan Valouch and Hana Urbancokova \\ Faculty of Applied Informatics, Nad Stráněmi 4511, 76005 Zlín, Czech Republic \\ *skovar@fai.utb.cz
}

\begin{abstract}
Currently, electromagnetic interference constitutes one of the major complications for a function of electronic or electrical devices. Because these devices are constantly exposed to effects of electromagnetic radiation, it is desirable to increase the electromagnetic immunity of device. One of the possibilities is to applicate the suitable shielding materials which can protect the device against the radiated electromagnetic emissions. This paper devotes to finding suitable materials for shielding security devices.
\end{abstract}

\section{Introduction}

Electromagnetic interference has become the serious problem for all electronic and electrical devices; that is why the demand for security of devices against this danger has increased. This paper describes one of the ways how to ensure the electromagnetic immunity of device against radiated electromagnetic emissions. This way is the use of shielding material. The authors of this publication used CST Studio Suite simulation software to calculate shielding effectiveness of materials. The research is focused especially on security devices, where the great emphasis is placed on reliability.

Electromagnetic interference can be limited in three main areas, namely at the source of the disturbance, at the receiver and in the transmission route. For the purpose of this work, it is necessary to restrict noise coming into the receiver because there are many interference sources and it is not possible to eliminate all of them. Depending on the method of interference propagation, the means to reduce unwanted noise fall into two categories, namely disturbance by conduction and radiation. In the case of conducted interference, the device is equipped with EMI filters, chokes, capacitors; it is also possible to change the transmission medium or arrangement of circuits. Radiated interference is reduced by selecting a suitable shielding. [1]

Shielding can be defined as a structural means to reduce interfering electromagnetic fields within a defined area. In other words, it protects the devices against unwanted external electromagnetic interference and simultaneously it prevents leakage of electromagnetic disturbance from the device. [1]

\section{Shielding Effectiveness}

The significant parameter in this area is shielding effectiveness that describes how the material eliminates the effects of electromagnetic radiation from the interference source. [1] According to [2] and [3], this parameter can be described by the following equation.

$$
S E=10 \cdot \log \frac{P_{1}}{P_{2}}[d B]
$$

Individual characters indicate:

$\mathrm{P}_{1}$ - power generated by interference source;

$\mathrm{P}_{2}$ - power passing through the shielding material.

This equation can be adjusted into a form which better corresponds to the physical mechanisms of the shielding effect. [1] This adjustment is described in publications [2] and [3].

$$
S E=R+A+M[d B]
$$

Individual characters indicate:

$\mathrm{R}$ - attenuation by reflection;

A - absorbent attenuation;

$\mathrm{M}$ - attenuation caused by multiplied reflection.

\subsection{Attenuation by Reflection}

This type of attenuation indicates how much energy is reflected at the interface between the dielectric with the impedance of $Z_{0}$ and the metal barrier with the impedance of $Z_{\mathrm{M}}$. The same situation occurs on the output between the metal barrier and the dielectric. [1] According to [2] and [3], the attenuation can be written as follows.

$$
\begin{gathered}
R=20 \cdot \log \left|\frac{Z_{0}+Z_{M}}{2 Z_{M}} \cdot \frac{Z_{0}+Z_{M}}{2 Z_{0}}\right|[d B] \\
R=R_{1}+R_{2}[d B]
\end{gathered}
$$

Individual characters indicate: 
$\mathrm{Z}_{0}$ - impedance of environment (dielectric);

$\mathrm{Z}_{\mathrm{M}}$ - impedance of material.

\subsection{Absorbent Attenuation}

This type of attenuation occurs by absorption of energy by the shielding material due to heat losses. [1] According to [2] and [3], the equations can be written as follows.

$$
\begin{aligned}
& A=20 \cdot \log e^{\frac{t}{\delta}}[d B] \\
& \delta=\sqrt{\frac{2}{\varpi \mu \sigma}}
\end{aligned}
$$

Individual characters indicate:

$\mathrm{t}$ - material thickness;

$\delta$ - intrusion depth;

$\sigma$ - conductivity;

$\mu$ - permeability;

$\omega-$ wave frequency.

\subsection{Attenuation Caused by Multiplied Reflection}

In the case, when the electromagnetic wave passes through the shielding material, then there are multiple reflections on the interfaces between environments. If $(\mathrm{t}$ $>>\delta$ ), the impact of multiple reflections is negligible; conversely, if $(\mathrm{t}<<\delta)$ then the attenuation is negative and shielding effectiveness decreases. According to the information given in publications [2] and [3], the attenuation may be described by the following equation. [1]

$$
M=20 \cdot \log \left|1-\left(\frac{Z_{0}-Z_{M}}{Z_{0}+Z_{M}}\right)^{2} \cdot e^{-\frac{2 t}{\delta}} \cdot e^{-j \frac{2 t}{\delta}}\right|[d B](6)
$$

Individual characters indicate:

$\mathrm{Z}_{0}$ - impedance of environment (dielectric);

$\mathrm{Z}_{\mathrm{M}}$ - impedance of material.

$\delta$ - intrusion depth.

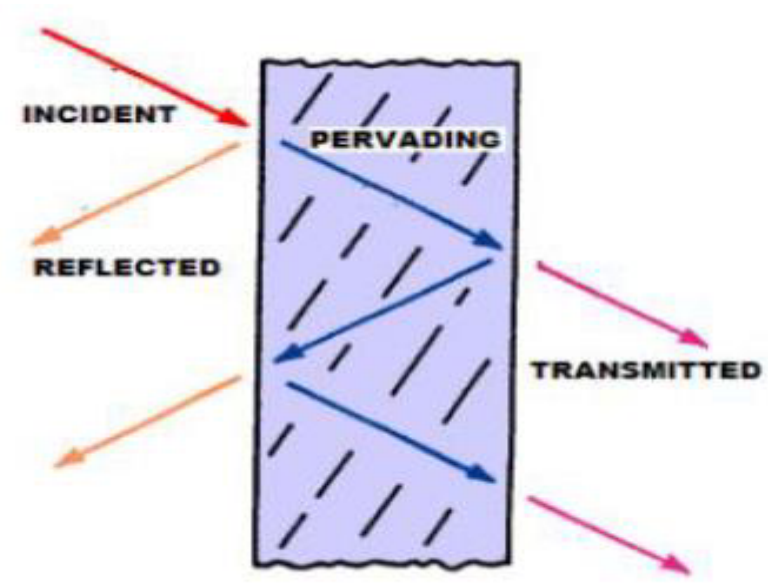

Fig. 1. Principle of Attenuation by Multiplied Reflection. [3]

\section{Process of Simulation}

The whole process of calculation of shielding effectiveness was performed using CST Studio Suite simulation software. The software is suitable for this experiment because it includes a wide database of materials. As representatives of shielding materials, steel and aluminium were selected. These materials are readily available and suitable for use with security devices. In addition, both materials are relatively cheap.

The process of simulation began by modelling the shielding material whose dimensions are $1 \times 1 \mathrm{~m}$ and thickness is $1 \mathrm{~mm}$. The receiver and transmitter are located facing each other on both sides of the material. The distance of transmitter and receiver from the material under test is $0.5 \mathrm{~m}$. The plane wave serves the source of the electromagnetic field and the probe receives the intensity of field penetrated through the shielding material. For an idea, Fig. 2 illustrates the process of testing where TX antenna replaces the source of the field and the RX antenna substitutes the probe.

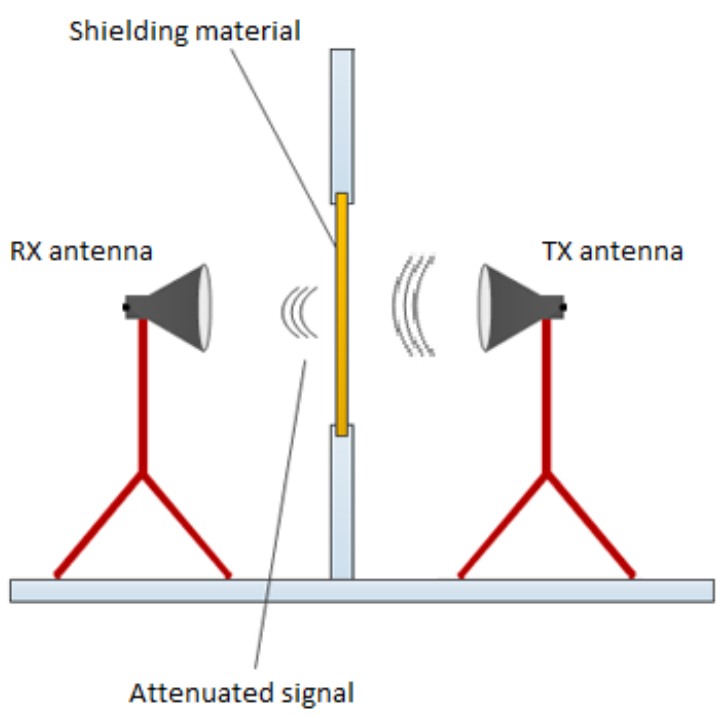

Fig. 2. Principle of Testing of Shielding Effectiveness. [4]

\subsection{Shielding materials}

The shielding material is one of the most famous ways of the device to protect the device against radiated electromagnetic interference. Shielding material can eliminate the level of disturbance and at the same time, it does not require intervention into the electronics of the device. As mentioned above, this paper describes only several representatives of potential materials for shielding purpose. Because CST Studio software includes a large number of materials, the paper describes the properties of selected materials in Tab. 1 and 2 . It is necessary to remark that the data is taken from the software database.

Tab. 1. Parameters of Aluminum

\begin{tabular}{|l|l|l|}
\hline Name & Value & Unit \\
\hline Type & Lossy metal & - \\
\hline Mue & 1 & - \\
\hline
\end{tabular}




\begin{tabular}{|l|l|l|}
\hline $\begin{array}{l}\text { Electrical } \\
\text { conductivity }\end{array}$ & $3.56 \mathrm{e}+007$ & $\mathrm{~S} / \mathrm{m}$ \\
\hline Rho & 2700 & $\mathrm{Kg} / \mathrm{m}^{3}$ \\
\hline $\begin{array}{l}\text { Thermal } \\
\text { conductivity }\end{array}$ & 237 & $\mathrm{~W} /(\mathrm{mK})$ \\
\hline Heat capacity & 0.9 & $\mathrm{~kJ} /(\mathrm{kgK})$ \\
\hline Diffusivity & $9.75309 \mathrm{e}-005$ & $\mathrm{~m}^{2} / \mathrm{s}$ \\
\hline Young's modulus & 69 & $\mathrm{kN} / \mathrm{mm}^{2}$ \\
\hline Poisson's ratio & 0.33 & - \\
\hline Thermal expansion & 23 & $1 \mathrm{e}-6 / \mathrm{K}$ \\
\hline
\end{tabular}

Tab. 2. Parameters of Steel

\begin{tabular}{|l|l|l|}
\hline Name & Value & Unit \\
\hline Type & Lossy metal & - \\
\hline Mue & 1 & - \\
\hline $\begin{array}{l}\text { Electrical } \\
\text { conductivity }\end{array}$ & $6.993 \mathrm{e}+006$ & $\mathrm{~S} / \mathrm{m}$ \\
\hline Rho & 7870 & $\mathrm{Kg} / \mathrm{m}^{3}$ \\
\hline $\begin{array}{l}\text { Thermal } \\
\text { conductivity }\end{array}$ & 65.2 & $\mathrm{~W} /(\mathrm{mK})$ \\
\hline Heat capacity & 0.45 & $\mathrm{~kJ} /(\mathrm{kgK})$ \\
\hline Diffusivity & $1.84103 \mathrm{e}-005$ & $\mathrm{~m}^{2} / \mathrm{s}$ \\
\hline $\begin{array}{l}\text { Young's } \\
\text { modulus }\end{array}$ & 205 & $\mathrm{kN} / \mathrm{mm}^{2}$ \\
\hline Poisson's ratio & 0.29 & - \\
\hline $\begin{array}{l}\text { Thermal } \\
\text { expansion }\end{array}$ & 13.5 & $1 \mathrm{e}-6 / \mathrm{K}$ \\
\hline
\end{tabular}

\section{Results}

This section describes the results of the electromagnetic simulation which was created by CST Studio software. A number of shielding materials for the purposes of this research is huge; despite this fact, this paper includes only several representatives. Results in this section depict attenuation of the electromagnetic field through the shielding material and it helps to create an idea which material is the suitable choice for increasing of electromagnetic immunity.

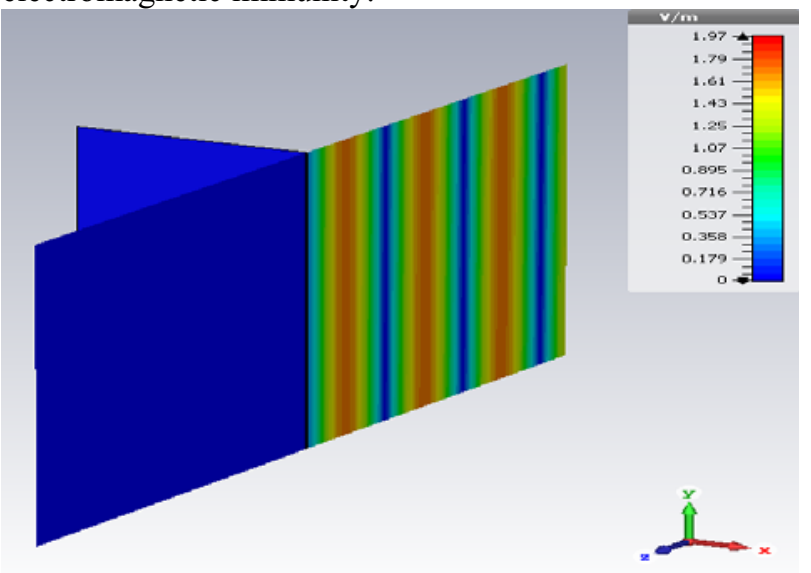

Fig. 3. Shielding Effectiveness.

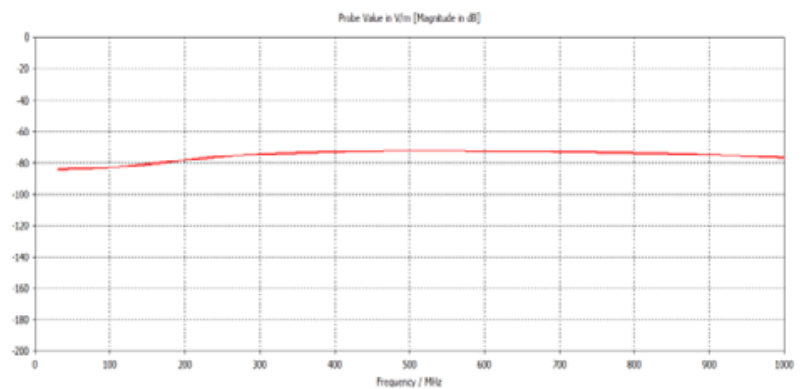

Fig. 4. Shielding Effectiveness of Aluminium Material. [1]

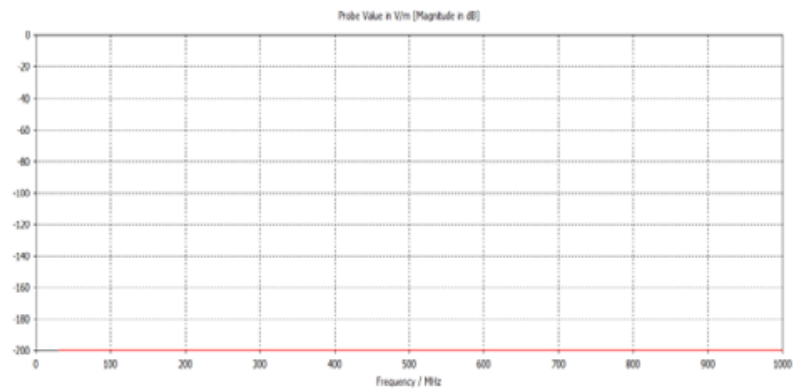

Fig. 5. Shielding Effectiveness of Steel Material. [1]

To ensure all functions of safety devices, cabling must be lead throughout the shielding material for transferring data or to supply power to the device. Therefore, copper wire with a diameter about $1 \mathrm{~mm}$ is lead throughout the material. The results of shielding effectiveness can be affected by selected wire. It includes the shape, diameter or load of wire.

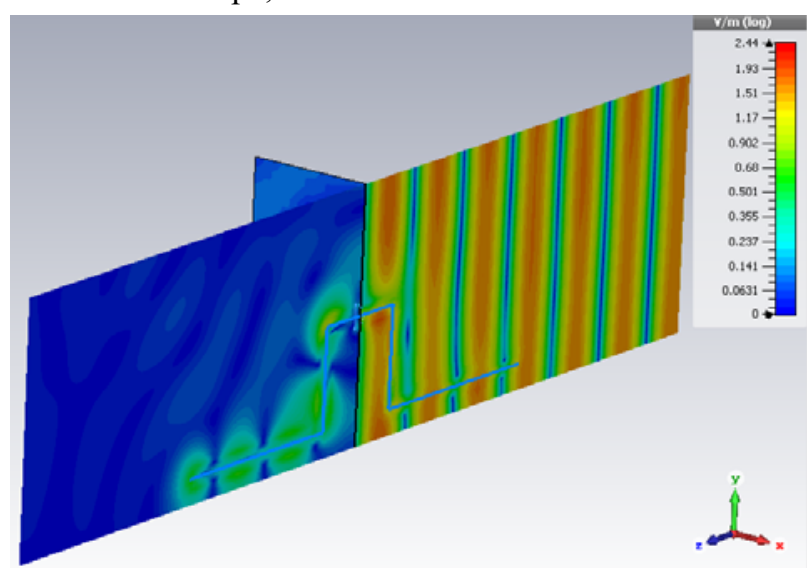

Fig. 6. Shielding Effectiveness of Aluminium when Copper Wire Passing through Material.

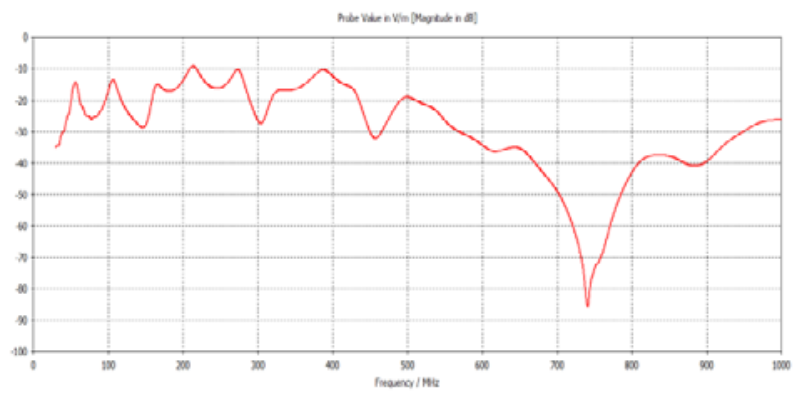

Fig. 7. Shielding Effectiveness of Aluminium Material through Which Passing Copper Wire. [1] 


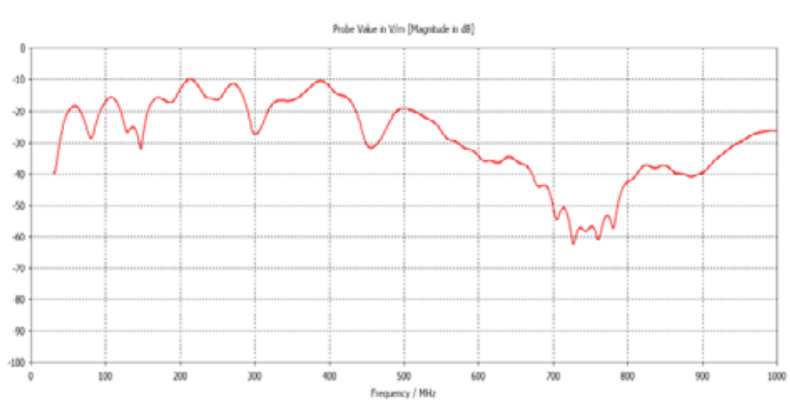

Fig. 8. Shielding Effectiveness of Steel Material through Which Passing Copper Wire. [1]

\section{Conclusion}

The paper describes the calculation of shielding effectiveness of material for the security device. Because the important factor of security devices is the reliability, the great emphasis should be placed on the electromagnetic immunity. This article summarises one of the ways how to protect the electronic and electric device.

Results of simulations indicate that the use of steel is the suitable way to protect device because it is able to resist the effect of the electromagnetic field. Conversely, the resistance of aluminium to the electromagnetic field is not as high as for steel. The field penetrates with certain attenuation.

In the case, that a wire is led throughout the shielding material, the field can couple to the wire and pass through a sealed material. Therefore, it is necessary to use the shielding wire to protect security devices.

The purpose of this paper is to expand the existing knowledge of shielding materials for security devices. This article will serve as a basis for future research in this research field.

The work was funded with the support of the Internal Grant Agency of Tomas Bata University under the project No. IGA/CebiaTech/2016/005, and support of research project No. LO1303 (MSMT-7778/2014) by the Ministry of Education, Youth and Sports of the Czech Republic within the National Sustainability Programme and also by the European Regional Development Fund under the project CEBIA-Tech No. CZ.1.05/2.1.00/03.0089.

\section{References}

1. S. Kovar. Immunity of camera systems against electromagnetic interference. Zlin (2017). Treatise on doctoral thesis. Faculty of applied informatics in Zlin. Supervisor doc. Mgr. Milan Adamek, Ph.D.

2. M. Pospislik, T. Riha, M. Adamek, Rui M. S. Silva. W.S.E.A.S.T.C.S, 14 (2015)

3. J. Svacina. Electromagnetic compatibility: principles and notes. Issue No. 1. (2001), 156 p. ISBN 8021418737. (in Czech)

4. Shielding Effectiveness Testing. Rhein Tech Laboratories, Inc. [online]. Available at: www.rheintech.com/what-we-do/our-emc-testingservices/shielding-effectiveness
5. D. Kovac, I. Kovacova, J. Kanuch. EMC in terms of theory and applications. ISBN 80-7300-202-7. 1 (2006)

6. H. Ott. Electromagnetic Compatibility. ISBN 978-0470-18930-6. (2009) 